\title{
Improved simulation of precipitation in the tropics using a modified BMJ scheme in the WRF model
}

\author{
R. M. Fonseca ${ }^{1}$, T. Zhang ${ }^{2}$, and K.-T. Yong ${ }^{1,2}$ \\ ${ }^{1}$ Earth Observatory of Singapore, Nanyang Technological University, Singapore \\ ${ }^{2}$ School of Physical and Mathematical Sciences, Nanyang Technological University, Singapore \\ Correspondence to: K.-T. Yong (kohty@ntu.edu.sg)
}

Received: 24 March 2015 - Published in Geosci. Model Dev. Discuss.: 26 May 2015

Revised: 25 August 2015 - Accepted: 7 September 2015 - Published: 22 September 2015

\begin{abstract}
The successful modelling of the observed precipitation, a very important variable for a wide range of climate applications, continues to be one of the major challenges that climate scientists face today. When the Weather Research and Forecasting (WRF) model is used to dynamically downscale the Climate Forecast System Reanalysis (CFSR) over the Indo-Pacific region, with analysis (grid-point) nudging, it is found that the cumulus scheme used, Betts-Miller-Janjić (BMJ), produces excessive rainfall suggesting that it has to be modified for this region. Experimentation has shown that the cumulus precipitation is not very sensitive to changes in the cloud efficiency but varies greatly in response to modifications of the temperature and humidity reference profiles. A new version of the scheme, denoted "modified BMJ" scheme, where the humidity reference profile is more moist, was developed. In tropical belt simulations it was found to give a better estimate of the observed precipitation as given by the Tropical Rainfall Measuring Mission (TRMM) 3B42 data set than the default BMJ scheme for the whole tropics and both monsoon seasons. In fact, in some regions the model even outperforms CFSR. The advantage of modifying the BMJ scheme to produce better rainfall estimates lies in the final dynamical consistency of the rainfall with other dynamical and thermodynamical variables of the atmosphere.
\end{abstract}

\section{Introduction}

One of the major challenges facing regional climate modelers today is the accurate representation of the observed rainfall, particularly in areas with complex topography and landsea contrasts such as the Maritime Continent (hereafter MC).
The MC, which consists of the Malay Peninsula, the Greater and Lesser Sunda Islands and New Guinea, comprises small landmasses with elevated terrain and shallow seas. This is a region of conditional instability that plays an important role in the large-scale atmospheric circulation (Ramage, 1968). When used to simulate the climate of these regions, given their coarse horizontal resolutions, global climate models (hereafter GCMs) fail to capture many of the factors and processes that drive regional and local climate variability, including the regional topography, and so regional climate models (hereafter RCMs), forced by GCMs or reanalysis data, are used instead to better study the climate of the MC.

When running a RCM forced with coarse resolution data for lateral boundary conditions, and without any further constraints, the fields in the interior can be quite different from the driving fields (Bowden et al., 2012) meaning that some form of relaxation in the interior, either analysis (Stauffer and Seaman, 1990, 1991) or spectral (Waldron et al., 1996; von Storch et al., 2000) nudging, is required to keep the RCM from diverging too far from the coarse-grid data. In WRF (Weather Research and Forecasting), and in both analysis and spectral nudging, the horizontal winds $(u, v)$ and the potential temperature perturbation $\left(\theta^{\prime}\right)$ are relaxed towards a reference state. However, while in the former water the vapour mixing ratio $\left(q_{\mathrm{v}}\right)$ is also nudged, in the latter the geopotential height perturbation $\left(\varphi^{\prime}\right)$ is relaxed instead. The reason why moisture is not nudged in spectral nudging is because of its spatial distribution: it can have pronounced horizontal and especially vertical variations that are likely to be missed out by the coarse resolution reanalyses used to force the RCMs (Miguez-Macho et al., 2005). Given the importance of the water vapour distribution for the simulation 
(a)

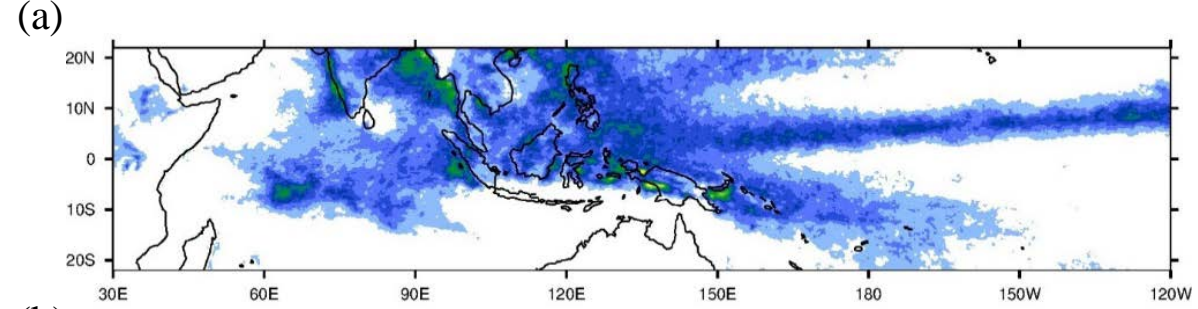

(b)

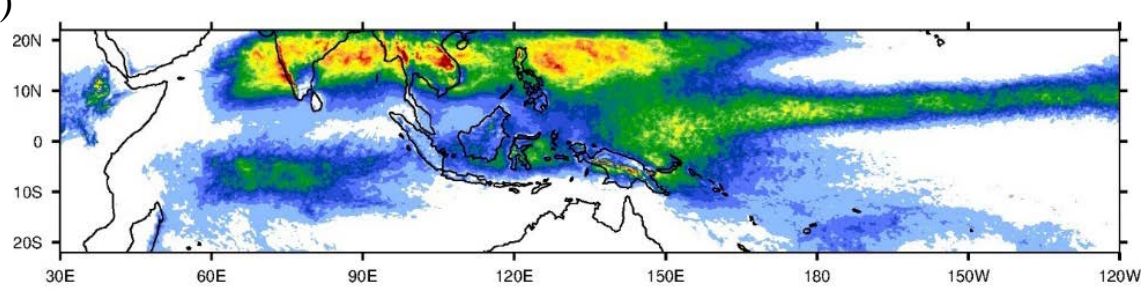

(c)

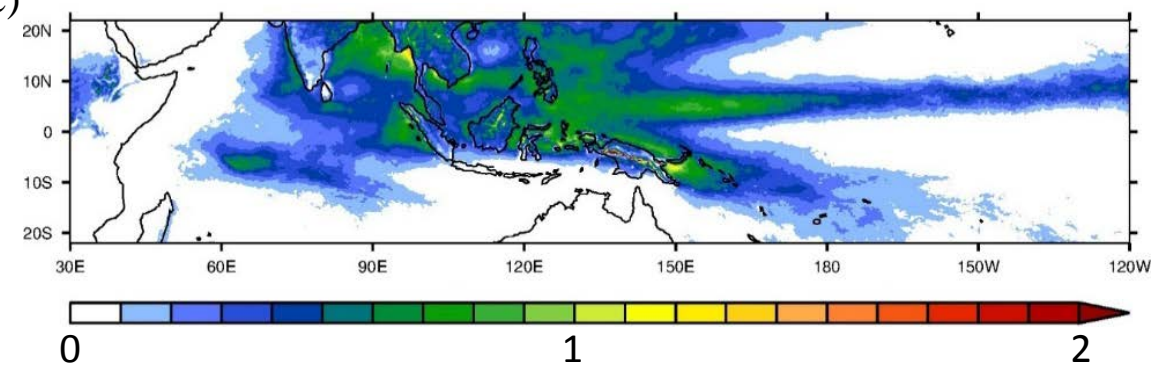

Figure 1. Precipitation rate (units of $\mathrm{mm} \mathrm{h}^{-1}$ ) averaged over June-September (JJAS) 2008 from (a) TRMM 3B42 version 6, (b) WRF run with no interior nudging and (c) WRF run with analysis nudging (see text for more details). In all plots the colour bar is linear with only the middle and end values shown.

of the tropical climate, analysis nudging is employed with the four fields nudged every $6 \mathrm{~h}$ on a timescale of $\sim 1 \mathrm{~h}$, a typical timescale used in nudging experiments (Stauffer and Seaman, 1991) and comparable to the critical timescale needed to properly reproduce the large-scale flow in the tropics (Hoskins et al., 2012). Nudging is only applied above the level of $800 \mathrm{hPa}$, and excluding the planetary boundary layer (hereafter PBL), as this configuration is found to give the best results for this region (J. Lo, personal communication, 2011). In addition, experimentation has shown that the precipitation over Southeast Asia is not very sensitive to the choice of the radiation, PBL, microphysics and land surface schemes but varies greatly with the choice of the cumulus scheme, with the Betts-Miller-Janjić (hereafter BMJ) scheme giving the smallest biases compared to the Kain-Fritsch (Kain and Fritsch, 1990, 1993; Kain, 2004) and Grell-Dévényi (Grell and Dévényi, 2002) schemes (J. Lo, personal communication, 2011). However, even when interior nudging is employed, WRF overestimates the observed rainfall, as given by TRMM (Tropical Rainfall Measuring Mission) 3B42 version 6 (Huffman et al., 2007), as seen in Fig. 1. Here, the rainfall rate over Southeast Asia averaged over the 2008 boreal summer (June-September, JJAS) for TRMM and the WRF experiments with and without analysis nudging is shown. As can be seen, without interior nudging the model produces excessive precipitation, particularly in the monsoon regions of southern Asia and to the east of the Philippines as a result of an incorrect representation of the large-scale atmospheric circulation (not shown). When analysis nudging is employed, the phase of the WRF precipitation is similar to that of TRMM's but the model continues to overestimate its amplitude. Given that most of the rainfall in these runs is generated by the cumulus scheme, the excessive precipitation produced suggests that the cumulus scheme may have to be modified at least for this region and possibly for the global tropics. The modification of the BMJ scheme to yield better tropical rainfall estimates will be addressed in this paper, which will also necessitate a comprehensive discussion of the BMJ scheme as implemented in WRF.

Despite recent improvements, much work is still needed to successfully develop an accurate representation of cumulus convection in numerical models. There are essentially two widely used types of convection parameterization schemes in weather and climate models: mass-flux or moisture convergence schemes (e.g. Arakawa and Schubert, 1974; Kain and Fritsch, 1990, 1993; Kain, 2004; Emanuel, 2001) and adjustment schemes (e.g. Betts, 1986; Betts and Miller, 1986; Janjić, 1994). In the former, a one-dimensional cloud model 
is used to compute the updraft and downdraft mass fluxes, and processes such as entrainment and detrainment are also normally considered. In contrast to these increasingly complex parameterizations which can involve detailed models of cloud processes, convective adjustment schemes take an "external" view of convection and simply relax the largescale environment towards reference thermodynamic profiles. One of such schemes is the Betts-Miller (hereafter BM) scheme that was originally developed by Alan Betts and Martin Miller in the 1980s and later modified by Zaviša Janjić in the 1990s to yield the current BMJ scheme. Janjić introduced a parameter called "cloud efficiency" that acts to reduce the precipitation in order to provide a smoother transition to gridresolved processes.

The WRF model (Skamarock et al., 2008), a fully compressible and non-hydrostatic model, is used in this work. WRF uses a terrain-following vertical coordinate derived from the hydrostatic pressure and surface pressure and the Arakawa $\mathrm{C}$ grid staggering for horizontal discretization. It is a community model used in a wide variety of applications including idealized simulations (e.g. Steele et al., 2013), hurricane research (e.g. Davis et al., 2008), regional climate research (e.g. Chotamonsak et al., 2011, 2012), weather forecasts (e.g. Done et al., 2004) and coupled atmosphere-ocean modelling (e.g. Samala et al., 2013). Here it is used to investigate the sensitivity of the cumulus precipitation to modifications made to the BMJ scheme and to assess the performance of the "modified BMJ" scheme in tropical belt simulations.

In Sect. 2 details about the model setup and methods used are presented. A discussion of the BMJ scheme is given in Sect. 3 while the results obtained in sensitivity experiments are shown in Sect. 4. In Sect. 5 the focus is on the modified scheme's performance in tropical belt experiments and in Sect. 6 the main conclusions are presented.

\section{Model, data sets and diagnostics}

In this study WRF is initialized with CFSR (Climate Forecast System Reanalysis) 6-hourly data (Saha et al., 2010; this data was downloaded from the Research Data Archive at the National Center for Atmospheric Research, Computational and Information Systems Laboratory, available online at http://rda.ucar.edu/datasets/ds093.0/), horizontal resolution of $0.5^{\circ} \times 0.5^{\circ}$, and is run for 1 day (2-3 March 2008), 1 month (1-30 April 2008), 6 months (1 April-30 September 2008) and 10 months (1 June 2008-31 March 2009) with a 1-day spin-up in the first set of experiments and a 1-month spin-up time in the last three prior to the stated simulated periods. The year of 2008 is chosen as according to Ummenhofer et al. (2009) it is a neutral year with respect to both El Niño-Southern Oscillation (ENSO) and the Indian Ocean Dipole (IOD). By choosing a neutral year, the impact of climatic anomalies is minimized. The physics parameterizations used include the WRF double-moment five- class microphysics scheme (Lim and Hong, 2010), the Rapid Radiative Transfer Model for Global models (RRTMG) for both shortwave and longwave radiation (Iacono et al., 2008), the Yonsei University planetary boundary layer (Hong et al., 2006) with Monin-Obukhov surface layer parameterization (Monin and Obukhov, 1954), the four-layer Noah land surface model (Chen and Dudhia, 2001) and to parameterize cumulus convection the BMJ scheme (Janjić, 1994). In all model runs 6-hourly sea surface temperature (hereafter SST) and monthly values of vegetation fraction and surface albedo are used. WRF is also run with a simple prognostic scheme of the sea surface skin temperature (Zeng and Beljaars, 2005) which takes into account the effects of the sensible, latent and radiative fluxes as well as diffusion and turbulent mixing processes in the vertical. In all model simulations nudging is applied at the lateral boundaries over a nine-grid-point transition zone while in the top $5 \mathrm{~km}$ Rayleigh damping is applied to the wind components and potential temperature on a timescale of $5 \mathrm{~s}$ (Skamarok et al., 2008).

The spatial domain on Mercator projection used for the 1-day, 1-month and 4-month diagnostics, shown in Fig. 1, extends from central Africa to the eastern Pacific and from about $25^{\circ} \mathrm{S}$ to $25^{\circ} \mathrm{N}$ with a horizontal grid spacing of $24 \mathrm{~km}$, while for the 10-month experiments a tropical belt extending from about $42^{\circ} \mathrm{S}$ to $45^{\circ} \mathrm{N}$ with a horizontal resolution of $30 \mathrm{~km}$ is used. In all model runs 37 vertical levels, more closely spaced in the PBL and in the tropopause region, are used with the model top at $30 \mathrm{hPa}$ and the highest undamped layer at about $70 \mathrm{hPa}$. The time step used is $1 \mathrm{~min}$ and the output is archived every $1 \mathrm{~h}$. Analysis nudging is applied to the horizontal winds $(u, v)$, potential temperature perturbation $\left(\theta^{\prime}\right)$ and water vapour mixing ratio $\left(q_{\mathrm{v}}\right)$. These fields are relaxed towards CFSR above $800 \mathrm{hPa}$ excluding the PBL on a timescale of $1 \mathrm{~h}$. The WRF rainfall is evaluated against the 3-hourly instantaneous multi-satellite rainfall estimates from TRMM, at a horizontal resolution of $0.25^{\circ} \times 0.25^{\circ}$, while all other fields are compared with CFSR. The model outputs on pressure and surface levels are bilinearly interpolated to the CFSR and TRMM grids for evaluation.

The model's performance is assessed with different verification diagnostics including the model bias, normalized bias $(\mu)$, correlation $(\rho)$, variance similarity $(\eta)$ and normalized error variance $\left(\alpha_{\epsilon}\right)$. The bias is defined as the discrepancy between the model and observations while the normalized bias is given by the bias divided by the standard deviation of the discrepancy between the model and observations (when $|\mu|<0.3$, the contribution of the bias to the total error is less than $\sim 5 \%$ and the biases will not be significant). The correlation is a measure of the phase agreement between the model and observations. The variance similarity is an indication of how the signal amplitude given by the model agrees with that observed and is defined as the ratio of the geometric mean to the arithmetic mean of the modelled and observed variances. The normalized error variance is the variance of the error arising from the disagreements in phase and amplitude and 


\section{DEFAULT WRF-BMJ SCHEME}

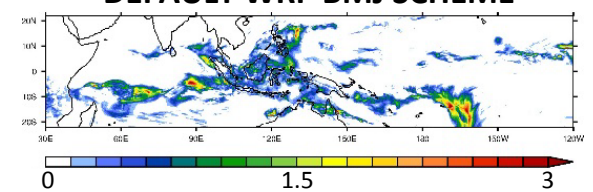

(a) $\tau=80 \mathrm{~min}$ (DEFAULT VALUE: $\tau=40 \mathrm{~min}$ )

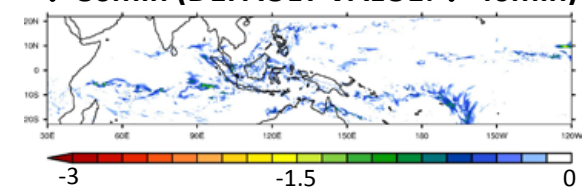

(b)

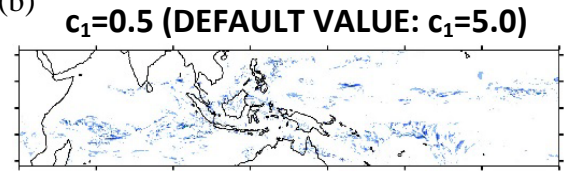

(e)

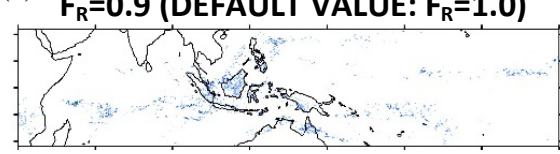

(h)

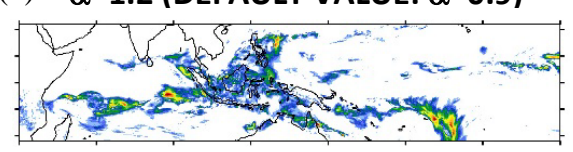

(c)

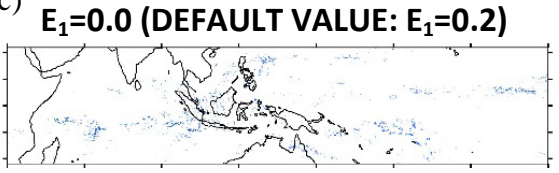

(f)

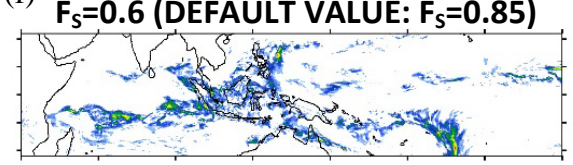

(i) $\alpha=1.5$ (DEFAULT VALUE: $\alpha=0.9$ )

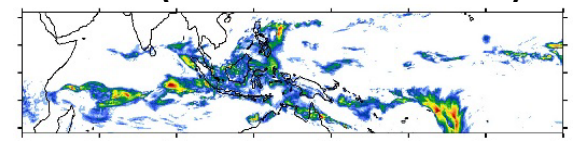

(d) $F_{1}=0.4$ (DEFAULT VALUE: $F_{1}=0.7$ )

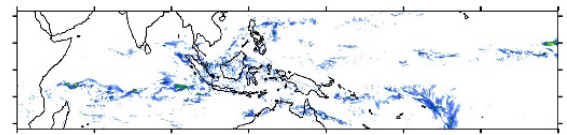

(g)

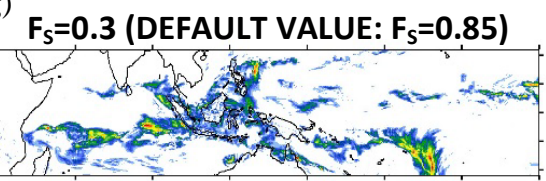

(j)

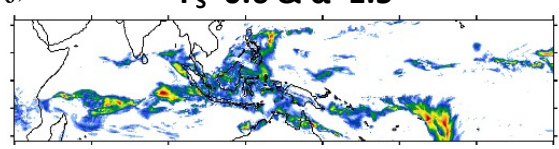

Figure 2. Precipitation rate from a 1-day WRF run (from 00:00 UTC on 2 March to 00:00 UTC on 3 March 2008) with the default WRFBMJ and modification in the rainfall rate for 10 experiments with a modified BMJ scheme using separately (a) $\tau=80 \mathrm{~min}$, (b) $c_{1}=0.5$, (c) $E_{1}=0.0$, , (d) $F_{1}=0.4$, (e) $F_{\mathrm{R}}=0.9$, (f) $F_{\mathrm{S}}=0.6$, (g) $F_{\mathrm{S}}=0.3$, (h) $\alpha=1.2$, (i) $\alpha=1.5$ and (j) $F_{\mathrm{S}}=0.6$ and $\alpha=1.5$ (units of $\mathrm{mmh}^{-1}$ ). The conventions are as in Fig. 1. Note that the colour scale is reversed to show drying upon modifications.

normalized by the combined modelled and observed signal variances. The best model performance corresponds to zero bias and $\alpha_{\epsilon}$ and to $\rho$ and $\eta$ equal to 1 . These diagnostics are defined in Eqs. (A1)-(A5) in Appendix A.

\section{Betts-Miller-Janjić (BMJ) cumulus scheme}

The BMJ scheme is an adjustment scheme where the essential principle lies in the relaxation of the temperature and humidity profiles towards reference thermodynamic profiles and precipitation is obtained as a necessary consequence from the conservation of water substance. The equations and factors used in the BMJ scheme, as we found implemented in WRF version 3.3.1, are given in Appendix B which the reader is encouraged to consult. We found the following two main differences in WRF's default implementation of the original formulation as defined in Betts (1986) and Janjić (1994).

- In the definition of the potential temperature reference profile, (B8), the factor $\alpha$ used is 0.9 as opposed to 0.85 as suggested by Betts (1986). A larger $\alpha$ leads to a warmer and more moist reference profile and therefore to a reduction in the precipitation produced by the cumulus scheme.
- The factor $F_{\mathrm{S}}$, used in the definition of the humidity reference profile for deep convection, Eqs. (B12)-(B14), is set to 0.85 while in Janjić (1994) a value of 0.6 is used. The smaller $F_{\mathrm{S}}$ is, the more moist the humidity reference profile will be and, therefore, the smaller the amount of precipitation generated by the scheme.

In Sect. 4.1 the sensitivity of the precipitation produced by this scheme to $\alpha$ and $F_{\mathrm{S}}$, as well as to the cloud efficiency $E$ and the convective adjustment timescale $\tau$, will be investigated.

\section{Sensitivity experiments}

\subsection{One-day diagnostics}

The aim of these experiments is to investigate the sensitivity of the precipitation produced by the BMJ scheme to changes in some of the parameters used in the scheme. In particular, as the default WRF-BMJ implementation scheme produces excessive rainfall over Southeast Asia, as shown in Fig. 1, in this section different ways of reducing the cumulus precipitation are explored in order to determine which ones are more efficient.

WRF is run from 00:00 UTC on 1 March to 00:00 UTC on 3 March 2008 with the first day regarded as model spin-up. 
The results are shown in Fig. 2. Here the precipitation rate obtained with the default BMJ scheme as implemented in WRF version 3.3.1 (control run) is plotted together with the modification in the rainfall rate for 10 experiments with a modified BMJ scheme: in the first experiment the sensitivity to the convective adjustment timescale $\tau$ is explored, in the next three the sensitivity to modifications in some of the parameters used in $F(E)$ (namely $c_{1}, E_{1}$ and $F_{1}$ ) is assessed while in the other six experiments the sensitivity to changes in the temperature and humidity reference profiles through modifications in $\alpha, F_{\mathrm{S}}$ and $F_{\mathrm{R}}$ is examined.

Given that the precipitation produced by the BMJ scheme is proportional to $F(E)$, Eq. (B7), a linear function of the cloud efficiency, $E$, and inversely proportional to the adjustment timescale $\tau$, the cumulus rainfall can be reduced by decreasing $F(E)$ and increasing $\tau$. The former can be achieved by lowering the constant $c_{1}$ used in the definition of the cloud efficiency (B5), reducing $F_{1}$ or increasing $E_{1}$ (a higher $E_{1}$ also means a more moist humidity reference profile and less rainfall). Figure 2 shows the difference in the rainfall rate, with respect to the default WRF-BMJ implementation, when $\tau$ is doubled ( $\tau=80 \mathrm{~min}$ ), $c_{1}$ is set to one tenth of its original value $\left(c_{1}=0.5\right)$ and when $E_{1}=0$ and $F_{1}=0.4$. The impact of changing these parameters on the cumulus rainfall is negligible. Similar results are obtained to changes in $F_{2}$ and $E_{2}$ (not shown), which is not surprising as changing $F_{2}$ and $E_{2}$ is equivalent to changing $\tau$ and $c_{1}$, respectively. Hence, the precipitation produced by the BMJ scheme is not very sensitive to changes in $F(E)$ and $\tau$.

The rainfall produced by the BMJ scheme can also be modified by changing the reference temperature and/or humidity profiles. The temperature reference profile, defined in Eq. (B8), includes a parameter $\alpha$ that when increased will give a warmer (and hence more moist) profile and therefore a reduction in the precipitation. The precipitation can also be decreased by making the humidity reference profile more moist, which can be achieved by reducing $F_{\mathrm{S}}$ or $F_{\mathrm{R}}$, Eqs. (B12)-(B14). The default value of $F_{\mathrm{R}}$ is 1 and an experiment is performed where it is reduced to 0.9. As shown in Fig. 2e, the BMJ scheme's rainfall is not sensitive to changes in $F_{\mathrm{R}}$. The default values of $F_{\mathrm{S}}$ and $\alpha$ are 0.85 and 0.9 , respectively, and experiments are performed where $F_{\mathrm{S}}$ is reduced to 0.6, the value suggested by Janjić (1994), and 0.3, and $\alpha$ is increased to 1.2 and 1.5. One last run in which both parameters are modified ( $F_{\mathrm{S}}$ is reduced to 0.6 and $\alpha$ increased to 1.5) is also performed. As seen in Fig. 2, the BMJ scheme's rainfall is very sensitive to changes in these two parameters, in particular to $\alpha$ : in fact, when $\alpha$ is set to 1.5 the cumulus scheme produces almost no precipitation (i.e. the convection shuts down).

In conclusion, in 1-day runs it is found that the precipitation produced by the BMJ scheme is not sensitive to changes in the cloud efficiency $E$ and $F(E)$ but varies greatly when the humidity and temperature reference profiles are modified. In the next section, results from 2-month runs performed with a modified BMJ scheme using the new values of $F_{\mathrm{S}}$ and $\alpha$ to further assess how the rainfall produced in those runs are compared to those obtained with the default WRF-BMJ implementation and observations (TRMM).

\subsection{One-month diagnostics}

The impact on precipitation due to changes in the temperature and humidity reference profiles will now be assessed in 1-month runs. WRF is run from 1 March to 30 April 2008, with the first month being regarded as spin-up. The precipitation rate averaged over April for the experiments with the default BMJ scheme and five modified BMJ schemes is shown in Fig. 3. In the first two, the humidity reference profile is more moist than in the default version of the scheme, with $F_{\mathrm{S}}$ changed to 0.6 and 0.3 , but no changes are made to the temperature reference profile; in the following two the temperature reference profile is warmer (and hence the humidity reference profile is more moist) with $\alpha$ set to 1.2 and 1.5; finally, in the last experiment $F_{\mathrm{S}}$ is reduced to 0.6 and $\alpha$ increased to 1.5 .

When the default WRF-BMJ implementation is used the model overestimates the observed rainfall mainly in the MC, eastern Indian Ocean, central tropical Pacific and in the South Pacific Convergence Zone (hereafter SPCZ). However, the other diagnostics are quite high with typical values of 0.7 0.8 for $\rho, 0.8-0.9$ for $\eta$ and $0.2-0.3$ for $\alpha_{\epsilon}$ and suggesting that WRF captures well the phase and variance of the observed rainfall resulting in small errors in the rainfall pentad series. As expected, in regions that typically receive very little precipitation, such as the Australian desert and southeastern parts of the Arabian Peninsula, these diagnostics are rather low scores.

Regarding the experiments with a modified BMJ scheme, when $F_{\mathrm{S}}$ is set to 0.6 , the value recommended by Janjić (1994), there is a much better agreement with TRMM except over the high terrain (in particular in the islands of New Guinea and Borneo) where the model overestimates the observed rainfall. In these regions the precipitation is mostly produced by the microphysics scheme (not shown). However, there is not much of an improvement in the other three diagnostics as they are already good. When a smaller value of $F_{\mathrm{S}}$ is used, corresponding to an even more moist humidity reference profile, there is a significant reduction in the precipitation over the whole domain, with the model now producing less rainfall than TRMM and with a slight worsening of the other diagnostics in particular of $\eta$ and $\alpha_{\epsilon}$ over the eastern Indian Ocean, MC and western Pacific. As found in the previous section, the sensitivity of the cumulus precipitation to changes in the temperature reference profile is even larger: when $\alpha$ is increased to 1.2 the scheme produces very little rainfall and a further increase to 1.5 leads to precipitation being confined mainly to the ITCZ (Intertropical Convergence Zone), SPCZ and the high terrain, indicating that the convection nearly shuts down. For these experiments 

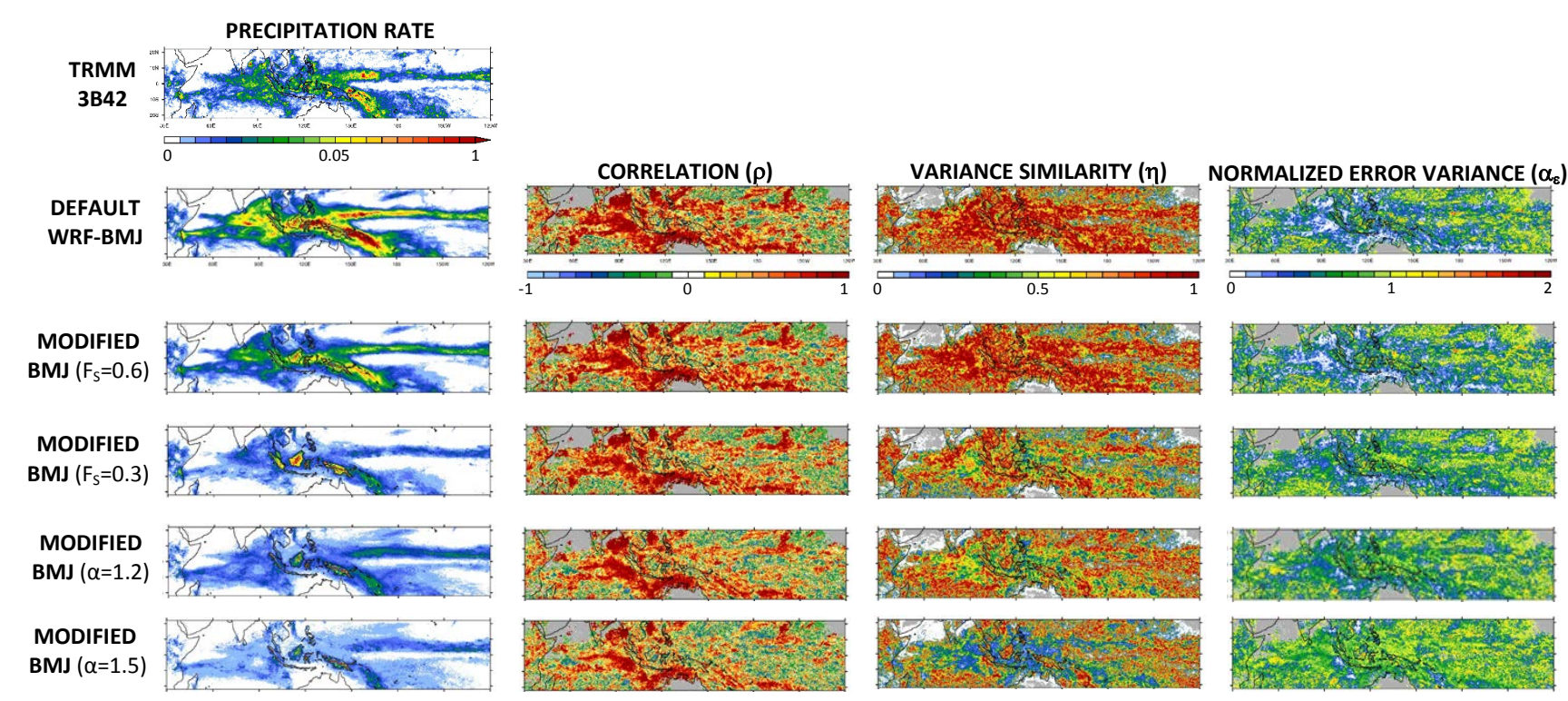

MODIFIED BMJ

$\left(F_{s}=0.6 \& \alpha=1.5\right)$
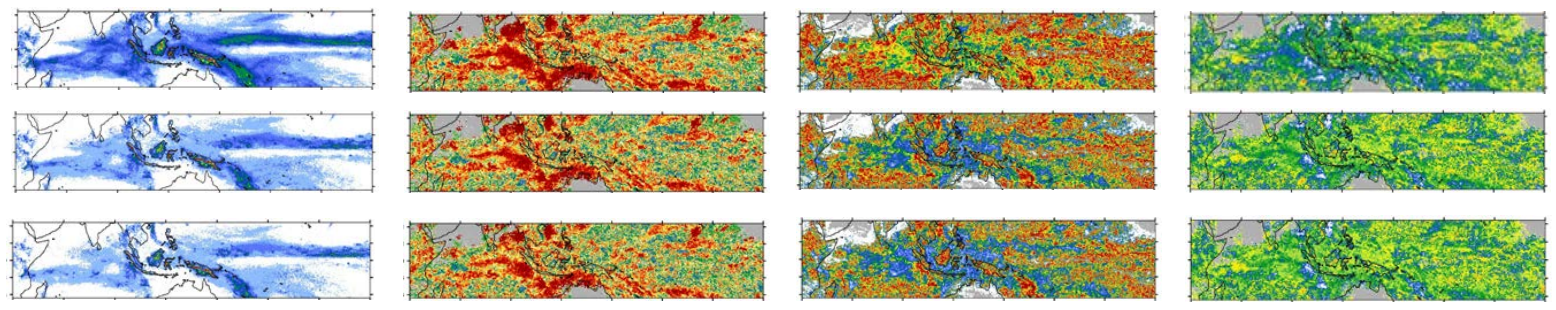

Figure 3. Precipitation rate $\left(\mathrm{mmh}^{-1}\right)$ from TRMM and WRF and model correlation $(\rho)$, variance similarity $(\eta)$ and normalized error variance $\left(\alpha_{\varepsilon}\right)$ with respect to TRMM for the experiments with the default BMJ scheme and with five modified versions of the BMJ scheme averaged over April 2008. The conventions are as in Fig. 1 with regions where $\rho, \eta$ and $\alpha_{\varepsilon}$ are infinite shaded in grey.

there is a significant deterioration of the other three diagnostics, in particular of $\eta$ and $\alpha_{\epsilon}$. When $\alpha$ is increased to 1.5 and $F_{\mathrm{S}}$ decreased to 0.6 the model performance is similar to that obtained when only $\alpha$ is set to 1.5 but drier than when only $F_{\mathrm{S}}$ is set to 0.6 , stressing the fact that $\alpha$ is the limiting factor and not $F_{\mathrm{S}}$.

In conclusion, in 2-month experiments it is found that, out of the different options considered, the best agreement with TRMM is obtained when $F_{\mathrm{S}}$ is set to 0.6 , the value recommended by Janjić (1994), corresponding to a more moist humidity reference profile while keeping $\alpha$ at its default value of 0.9. This new implementation of the BMJ scheme, hereafter called "modified" BMJ, will now be tested in 6-month runs.

\subsection{Four-month diagnostics}

In 1-month runs it is found that the best agreement in the rainfall rate between WRF and TRMM is obtained when $F_{\mathrm{S}}$ is set to 0.6 , corresponding to a more moist humidity reference profile. In this section the performance of this modified BMJ scheme will be tested in 6-month runs initialised on 1 April with a focus on the boreal summer season, JuneSeptember. In addition, this experiment is also repeated with no interior nudging and relaxing the water vapour mixing ratio, horizontal winds and potential temperature perturbation separately towards CFSR. The results are shown in Fig. 4.

As seen in Fig. 4, when the modified BMJ scheme is used there is a significant improvement in the representation of the observed rainfall, as given by TRMM, compared to that obtained with the default WRF-BMJ implementation: the positive biases with the default BMJ scheme over the MC and Southeast Asia are corrected when the modified BMJ scheme is used. In fact, with the modified BMJ scheme the model bias is only significant mainly over the high terrain, where most of the rainfall is actually produced by the microphysics scheme. There is an exception around Sri Lanka, however, where there is little precipitation in TRMM but WRF produces a considerable amount of rainfall and therefore the biases will be significant here. There is also some improvement in the other verification diagnostics (not shown).

In all WRF experiments discussed so far, analysis nudging was employed. However, it is of interest to assess the modified BMJ scheme's performance when no interior nudging is used. The fourth and fifth rows of Fig. 4 show the precipitation obtained with the default and modified BMJ schemes but with no interior nudging applied and they convey a very different picture: in this case there is almost no improvement in the simulation of the observed precipitation when the modified BMJ scheme is used, as the decrease in the cumulus rainfall is offset by an increase in the microphysics precipitation. This is an important result that suggests any change made to the BMJ scheme will be fruitless without interior (analysis) nudging. In the default configuration, as stated in Sect. 2, the horizontal winds $(u, v)$, potential temperature perturbation $\left(\theta^{\prime}\right)$ and water vapour mixing ratio $\left(q_{\mathrm{v}}\right)$ are relaxed towards CFSR. Three additional experiments are performed with the 


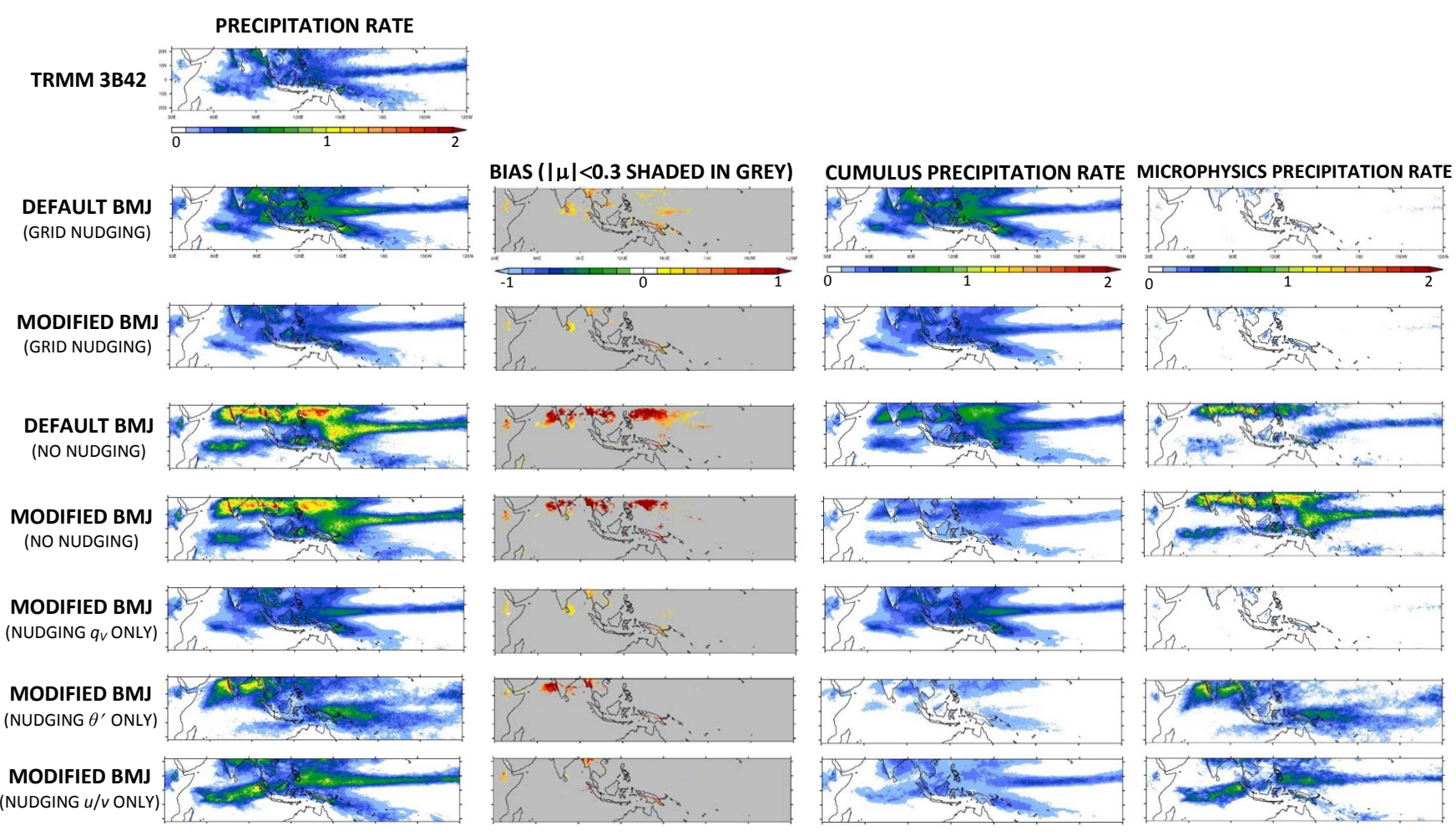

Figure 4. Precipitation rate $\left(\mathrm{mm} \mathrm{h}^{-1}\right)$ averaged over JJAS 2008 from TRMM and seven WRF experiments with the default BMJ and modified $\operatorname{BMJ}\left(F_{\mathrm{S}}=0.6\right)$ schemes both with and without analysis nudging and relaxing only the water vapour mixing ratio $(q \mathrm{v})$, horizontal winds $(u$, $v$ ) and potential temperature perturbation $\left(\theta^{\prime}\right)$ in the interior of the domain separately towards CFSR. Left to right: precipitation rate, model bias (regions where $|\mu|<0.3$ are shaded in grey) with respect to TRMM and precipitation rate from the cumulus and microphysics schemes. The conventions are as in Fig. 1.

modified BMJ scheme where these variables are nudged separately. As shown in Fig. 4, the crucial variable that has to be relaxed is $q_{\mathrm{v}}$ : in fact, when only this field is nudged the precipitation produced by the model is very similar to that obtained when all four fields are relaxed toward CFSR with similar contributions to rainfall from the cumulus and microphysics schemes. If analysis nudging is only applied to the temperature or horizontal winds there are much larger biases. When only the former is nudged there is excessive precipitation from microphysics off the east coast of India and the Bay of Bengal, as in the experiment with no interior nudging, because of an incorrect representation of the large-scale circulation, as well as to the northeast of New Guinea with the ITCZ in the Pacific displaced southwards. When only the horizontal winds are nudged there is excessive precipitation in a region aligned in the southwest-northeast direction to the west of Sumatra as well as along the ITCZ in the Pacific as a result of excessive moisture in those regions (not shown). In these two experiments, and as opposed to the ones where only $q_{\mathrm{v}}$ or all four fields are relaxed, the microphysics rainfall gives a contribution as large as, or even larger than, the cumulus rainfall to the total precipitation. It can be concluded that it is crucial to properly represent the water vapour mixing ratio in the tropics in order to simulate the observed precipitation. It is also important to stress that here the focus has just been on the precipitation and when only one of the referred fields is nudged separately there are noticeable errors in others and hence all four fields have to be nudged in order for the model to correctly simulate the atmospheric circulation over Southeast Asia (Bowden et al., 2013).

\section{Tropical belt experiments}

The performance of the modified BMJ will now be assessed for the whole tropics and for 11 months initialised on 1 May 2008 with the first month as spin-up. We focus on the boreal summer monsoon season, JJAS 2008, and winter monsoon season, December-February (hereafter DJFM) straddling 2008 and 2009. The results are shown in Fig. 5.

In the boreal summer, the precipitation produced by WRF in Southeast Asia in the tropical belt experiments is similar to that obtained in the smaller domain runs performed at $24 \mathrm{~km}$ horizontal resolution shown in Fig. 4. With the default WRFBMJ implementation, WRF produces excessive precipitation over most of Southeast Asia and the eastern equatorial Pacific with rainfall biases that are also significant over high 

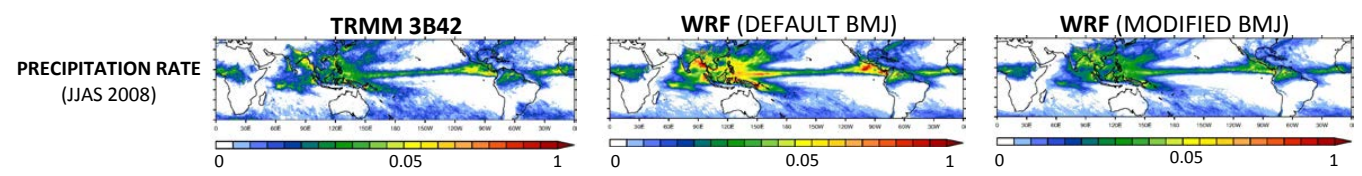

BIAS $(|\mu|<0.3$ SHADED IN GREY)
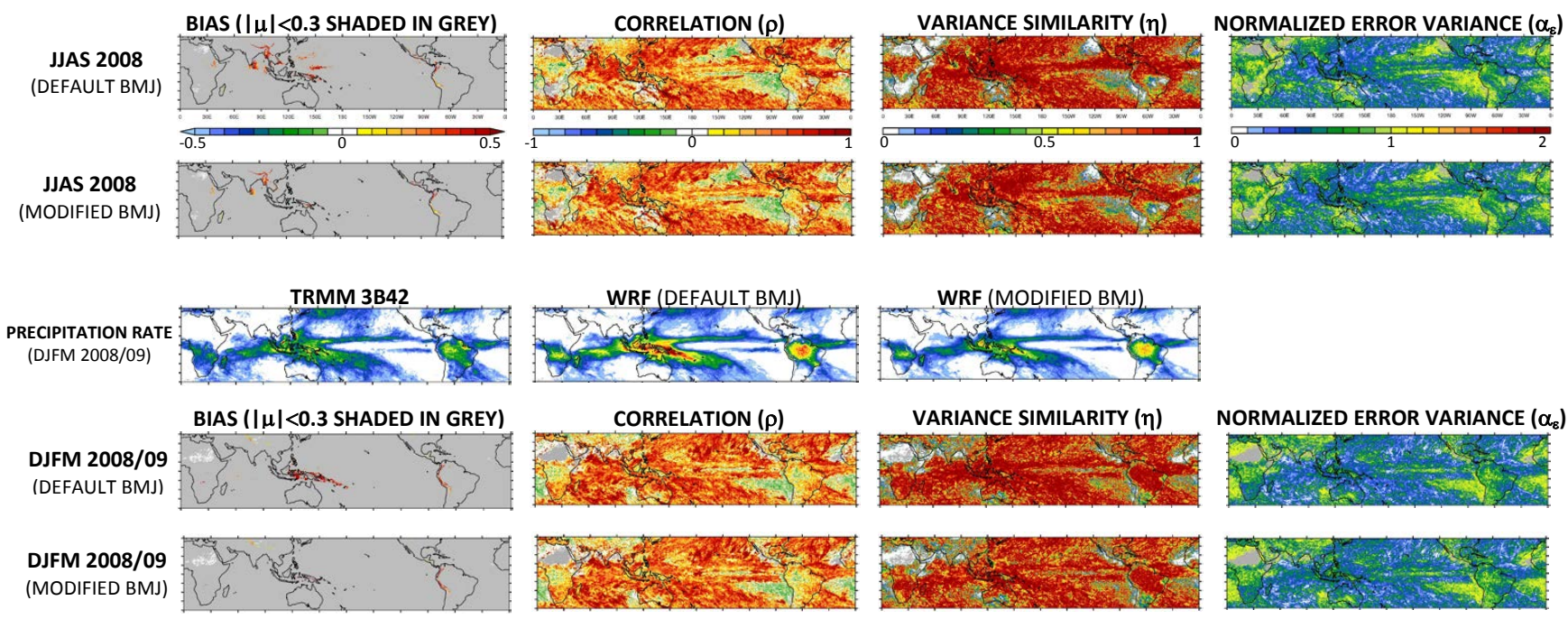

Figure 5. Precipitation rate $\left(\mathrm{mm} \mathrm{h}^{-1}\right)$ from TRMM and WRF and model biases (regions where $|\mu|<0.3$ are shaded in grey), correlation $(\rho)$, variance similarity $(\eta)$ and normalized error variance $\left(\alpha_{\varepsilon}\right)$ with respect to TRMM for the tropical belt experiments with analysis nudging and the default and modified BMJ schemes averaged over JJAS 2008 and DJFM 2008/2009. The conventions are as in Fig. 1 and, as in Fig. 3 , regions where $\rho, \eta$ and $\alpha_{\varepsilon}$ are infinite are shaded in grey.

terrain, particularly over the East African Highlands, the Himalayas, the Arakan Mountains in western Myanmar and the Andes. When the modified BMJ scheme is employed, there is a significant improvement with the biases being now restricted to the high terrain as well as around Sri Lanka (as explained before in Sect. 4). The change in the other verification diagnostics $\left(\rho, \eta\right.$ and $\left.\alpha_{\epsilon}\right)$ is small as they are already relatively good.

As also shown in Fig. 5, similar results are obtained for the boreal winter season: with the default WRF-BMJ implementation the model overestimates the precipitation in the $\mathrm{MC}$ and along the SPCZ, but these biases are largely corrected when the modified BMJ scheme is used. However, over land areas such as the Amazon and south-central Africa, despite some improvement, the model continues to overestimate the observed precipitation. This is because the convective clouds produced by the BMJ scheme are radiatively transparent so that surface temperature remains too warm during rainfall, an issue that will be addressed in a subsequent paper. As was the case for the summer season, very little improvement is seen in $\rho, \eta$ and $\alpha_{\epsilon}$ when the modified BMJ scheme is used with typical correlations of $0.6-0.8$, variance similarity close to 1 and normalized error variances of $0.3-0.4$ over most of the domain except in regions with light and irregular amounts of precipitation, such as eastern side of sub-tropical Pacific and Atlantic oceans and deserts in northern and southern Africa and the Arabian Peninsula, Tibetan Plateau, Australia and South America. The southern Amazon Basin experiences a dry season in boreal summer, so $\eta$ and $\alpha_{\epsilon}$ indicate bad model performance in that season.

The improvement in the representation of the observed precipitation when the modified BMJ scheme is used is not just confined to Southeast Asia in the boreal summer season but takes place across the whole tropics and in both monsoon seasons. It is important to note that not all biases are corrected, in particular over high terrain where most rainfall is produced by the microphysics scheme. In these regions WRF is known to overestimate the rainfall, as discussed in Teo et al. (2011), and an accurate simulation of the precipitation requires higher horizontal resolution to properly resolve the orography which we cannot afford computationally in this larger domain.

\section{Conclusions}

The accurate modelling of precipitation, in particular over complex topography and regions with strong land-sea contrasts such as the MC, continues to be one of the major challenges that atmospheric scientists face today. In this study the BMJ scheme, a convective adjustment scheme where temperature and humidity are relaxed towards reference profiles, as implemented in WRF version 3.3.1, is modified so that the precipitation produced by the model is in better agreement with that observed as given by TRMM. 
In 1-day runs the sensitivity of the precipitation to changes in some of the parameters used in the cumulus scheme is investigated. It is found that the rainfall is not sensitive to the following: $\tau$, the convective timescale; $F(E)$, a linear function of the cloud efficiency; and $F_{\mathrm{R}}$, the upper limit to dehumidification by rain formation. The same is not the case when the temperature and humidity reference profiles are modified by changes in the parameters $\alpha$ and $F_{\mathrm{S}}$. When the temperature reference profile is warmer (corresponding to a larger $\alpha$ ) and/or the humidity reference profile is more moist (corresponding to a larger $\alpha$ or a smaller $F_{\mathrm{S}}$ ) there is a decrease in the convective rainfall and vice versa.

In 1-month experiments it is found that, out of the different values of $\alpha$ and $F_{\mathrm{S}}$ considered, the best agreement of the model's precipitation with the one given by TRMM is obtained with a more moist humidity reference profile with the parameter $F_{\mathrm{S}}$ set to 0.6 , the value suggested by Janjić (1994). This new value is adopted as the modification to the BMJ scheme in subsequent work.

From the 4-month diagnostics during JJAS 2008, the rainfall generated by WRF with the modified BMJ scheme is found to be in close agreement with that of TRMM. In fact, the biases are now restricted to high terrain where most of the rainfall is generated by the microphysics scheme. In these experiments analysis nudging is applied in the interior of the domain. Experimentation showed that with no interior nudging the decrease in the rainfall given by the cumulus scheme is mostly offset by an increase in the microphysics rainfall. This result shows that any changes made to the BMJ scheme will only have an impact in the precipitation if some form of nudging in the interior of the model domain is applied. It is also found that the rainfall obtained when only specific humidity is nudged is similar to that obtained when wind and perturbation potential temperature are additionally nudged, stressing the importance of modelling well the water vapour distribution in the tropics to successfully produce the observed rainfall.

The performance of the modified BMJ scheme is further assessed in tropical belt experiments with the model run from 1 May 2008 to 31 March 2009 with a focus on the boreal summer monsoon, JJAS, and boreal winter monsoon, DJFM. It is found that for both seasons and for the whole tropics, with the modified BMJ scheme the model gives a better estimate of the observed precipitation than the default WRFBMJ implementation. However, WRF continues to overestimate the observed rainfall over high terrain where a higher horizontal resolution is needed to properly resolve the orography. Although there is a significant reduction in the bias with the modified BMJ scheme, the other three verification diagnostics considered $\left(\rho, \eta\right.$ and $\left.\alpha_{\epsilon}\right)$ do not show much of an improvement as they are already good.

To conclude, the modified BMJ scheme gives a better representation of the observed rainfall for the whole tropics in both winter and summer seasons, and will be of a great value to the research community working on tropical dynamics. Progress has also been made in understanding how the BMJ scheme, as implemented in WRF, interacts with other physics schemes, in particular with the microphysics scheme. 
Appendix A: Verification diagnostics

BIAS $=\langle\boldsymbol{D}\rangle=\langle\boldsymbol{F}\rangle-\langle\boldsymbol{O}\rangle$

$\mu=\frac{\langle\boldsymbol{D}\rangle}{\sigma_{D}}$

$\rho=\frac{1}{\sigma_{O} \sigma_{F}}\langle(\boldsymbol{F}-\langle\boldsymbol{F}\rangle) \cdot(\boldsymbol{O}-\langle\boldsymbol{O}\rangle)\rangle, \quad-1 \leq \rho \leq 1$

$\eta=\frac{\sigma_{O} \sigma_{F}}{\frac{1}{2}\left(\sigma_{O}^{2}+\sigma_{F}^{2}\right)}, \quad 0 \leq \eta \leq 1$

$\alpha_{\epsilon}=1-\rho \eta=\frac{\sigma_{D}^{2}}{\sigma_{O}^{2}+\sigma_{F}^{2}}, \quad 0 \leq \alpha_{\epsilon} \leq 2$

In the equations above $\boldsymbol{D}$ is the discrepancy between the model forecast $\boldsymbol{F}$ and the observations $\boldsymbol{O}, \sigma_{X}$ is the standard deviation of $X, \mu$ is the normalized bias, $\rho$ is the correlation coefficient, $\eta$ is the variance similarity, and $\alpha_{\epsilon}$ is the normalized error variance.

More information about these diagnostics can be found in Koh et al. (2012).

\section{Appendix B: BMJ equations for deep convection in WRF}

The equations shown in this section are the ones used in the BMJ scheme in WRF version 3.3.1 and are based on Betts (1986) and Janjić (1994).

In this cumulus scheme as explained in Betts (1986), the model first assesses whether there is convective available potential energy (CAPE) present and whether the cloud is sufficiently thick (i.e. $L_{\mathrm{B}}-L_{\mathrm{T}}>2$ or $p_{\mathrm{B}}-p_{\mathrm{T}}>10 \mathrm{hPa}$ ) where $L_{\mathrm{B}}$ and $L_{\mathrm{T}}$ are the cloud-base and cloud-top model levels and $p_{\mathrm{B}}$ and $p_{\mathrm{T}}$ the correspondent pressure levels; $L_{\mathrm{B}}$ is defined as the model level just above the lifting condensation level (LCL) and has to be at least $25 \mathrm{hPa}$ above the surface whereas $L_{\mathrm{T}}$ is defined as the level at which CAPE is maximum (i.e. level of neutral buoyancy, LNB) for the air parcel with the maximum equivalent potential temperature $\theta_{\mathrm{E}}$ in the depth interval [PSFC, PSFC $\times 0.6$ ] where PSFC is the surface pressure. If that is not the case there will be no convection and the scheme will abort. If all those conditions are met, the cloud depth is compared to a minimum depth given by

$D_{\min }=200 \mathrm{hPa}\left(\frac{\mathrm{PSFC}}{1013 \mathrm{hPa}}\right)$.

If the cloud depth is smaller than $D_{\text {min }}$, shallow convection is triggered, otherwise deep convection is considered. In both shallow and deep convection (Betts, 1986), temperature and humidity fields are adjusted as follows:

$$
\begin{aligned}
& \Delta T_{\mathrm{BM}}=T_{\mathrm{REF}}-T, \\
& \Delta q_{\mathrm{BM}}=q_{\mathrm{REF}}-q,
\end{aligned}
$$

where $\Delta T_{\mathrm{BM}}$ and $\Delta q_{\mathrm{BM}}$ are the Betts' adjustment of temperature $(T)$ and specific humidity $(q)$ in a model layer. Thus, the problem is reduced to defining the reference temperature and specific humidity reference profiles $T_{\text {ref }}$ and $q_{\text {ref }}$ for shallow and deep convection. In the BMJ scheme rainfall is only produced by deep convection, which is the topic of this Appendix.

\section{B1 Rainfall}

The BM scheme conserves enthalpy meaning that

$\sum_{p_{\mathrm{T}}}^{p_{\mathrm{B}}}\left(c_{P} \Delta T_{\mathrm{BM}}+L_{\mathrm{WV}} \Delta q_{\mathrm{BM}}\right) \Delta p_{\mathrm{L}}=0$,

where $c_{P}$ is the specific heat at constant pressure for dry air assumed to be constant, $L_{\mathrm{WV}}$ is the latent heat of vaporisation for water vapour, $\Delta p_{\mathrm{L}}$ is the thickness of the model layer bounded by the model level indices $L$ and $L+1$ in pressure coordinates. The total mass of water substance is conserved; hence, in the original BM scheme (Betts, 1986) the rainfall is given by

$\Delta P_{\mathrm{BM}}=\frac{1}{g \rho_{\mathrm{W}}} \sum \Delta q_{\mathrm{BM}} \Delta p_{\mathrm{L}}$,

where $\rho_{\mathrm{w}}$ is the density of liquid water, and $g$ is the acceleration of free fall.

In Janjić (1994), a parameter called cloud efficiency $(E)$ is introduced and is defined as

$E=c_{1} \frac{\bar{T} \Delta S}{c_{P} \sum \Delta T_{\mathrm{BM}} \Delta p_{\mathrm{L}}}$,

with

$$
\bar{T}=\frac{\sum T_{\mathrm{m}} \Delta p_{\mathrm{L}}}{p_{\text {bottom }}-p_{\text {top }}},
$$

$\Delta S=\sum\left(\frac{c_{P} \Delta T_{\mathrm{BM}}+L_{\mathrm{WV}} \Delta q_{\mathrm{BM}}}{T_{\mathrm{m}}}\right) \Delta p_{\mathrm{L}}$,

$T_{\mathrm{m}}=T+\frac{\Delta T_{\mathrm{BM}}}{2}$,

where $\bar{T}$ is the weighted mean temperature of the cloudy air column, $\Delta S$ is the entropy change per unit area for the cloudy air column multiplied by $g, T_{\mathrm{m}}$ is the mean temperature over the time step, and $c_{1}$ is a non-dimensional constant estimated experimentally and set to 5 . All summation symbols refer to summing over all cloudy layers $\left[L_{\mathrm{B}} L_{\mathrm{T}}\right]$.

The denominator of Eq. (B5) is proportional to the singletime-step rainfall from a model layer in the original BM 
scheme, Eq. (B4), and hence the cloud efficiency reduces when there is a propensity for heavy rain, partly correcting the tendency to overpredict intense rainfall in the original BM scheme.

In the default WRF-BMJ implementation, the precipitation $(\Delta P)$ and the adjustments in temperature and humidity ( $\Delta T$ and $\Delta q$ ) over one cumulus time step $(\Delta t)$ are given by

$$
\left\{\begin{array}{l}
\Delta P=\Delta P_{\mathrm{BM}} F(E) \Delta t / \tau \\
\Delta T=\Delta T_{\mathrm{BM}} F(E) \Delta t / \tau, \\
\Delta q=\Delta q_{\mathrm{BM}} F(E) \Delta t / \tau
\end{array}\right.
$$

where $F(E)$ is a linear function of the cloud efficiency given by

$$
F(E)=\left(1-\frac{\Delta S_{\min }}{\Delta S}\right)\left[F_{1}+\left(F_{2}-F_{1}\right)\left(\frac{E^{\prime}-E_{1}}{E_{2}-E_{1}}\right)\right]
$$

with $E^{\prime}$ constrained to be in the range $\left[E_{1} E_{2}\right]$ :

$$
E^{\prime}=\left\{\begin{array}{lll}
E_{1} & \text { if } & E \leq E_{1} \\
E & \text { if } & E_{1} \leq E \leq E_{2} \\
E_{2} & \text { if } & E \geq E_{2}
\end{array}\right.
$$

The constant $F_{1}=0.7$ is determined experimentally and $F_{2}=1$ for the chosen value of $\tau$, while $E_{1}=0.2$ is determined empirically in Janjić (1994) and $E_{2}=1$ for the chosen value of $c_{1}$. It is important to note that in Janjić (1994), $F(E)$ does not depend on the entropy change unlike the implementation we found in WRF version 3.3.1. In Eq. (B6) $\tau$ is the convective adjustment timescale set to $40 \mathrm{~min}$ (Betts, 1986).

If the change in entropy is small (or even negative), i.e. $\Delta S<\Delta S_{\min }=10^{-4} \mathrm{JK}^{-1} \mathrm{~m}^{-1} \mathrm{~s}^{-2}$, or very little (perhaps even negative) rainfall is obtained, i.e. $\sum \Delta T \Delta p_{\mathrm{L}} \leq$ $10^{-7} \mathrm{~K} \mathrm{~kg} \mathrm{~m}^{-1} \mathrm{~s}^{-2}$, shallow convection is triggered; otherwise, the BMJ scheme proceeds with deep convection. The reader is referred to Janjić (1994) for the documentation on shallow convection which we are not concerned with in this work.

\section{B2 Reference profiles for deep convection}

The first-guess potential temperature reference profile $\left(\theta_{\mathrm{REF}}^{\mathrm{f}}\right)$ for deep convection used in the BMJ scheme is assumed to have a vertical gradient that is a fixed fraction $\alpha$ of the vertical gradient of saturated equivalent potential temperature $\left(\theta_{\mathrm{ES}}\right)$ following a moist virtual adiabat (i.e. isopleth of virtual equivalent potential temperature) from the cloud base up to the freezing level. Above the freezing level, $\theta_{\mathrm{REF}}^{\mathrm{f}}$ slowly approaches and reaches the environmental $\theta_{\mathrm{ES}}$ at the cloud top. Thus, $\theta_{\mathrm{REF}}$ given is prescribed by

$\theta_{\mathrm{REF}}^{\mathrm{f}}\left(p_{\mathrm{B}}\right)=\theta\left(p_{0}, T_{0}\right)$,

$$
\left\{\begin{array}{ll}
p_{\mathrm{M}} \leq p_{L}<p_{\mathrm{B}}: & \theta_{\mathrm{REF}}^{\mathrm{f}}\left(p_{\mathrm{L}}\right)=\theta_{\mathrm{REF}}^{\mathrm{f}}\left(p_{L-1}\right) \\
& +\alpha\left[\theta_{\mathrm{ES}}\left(p_{\mathrm{L}}\right)-\theta_{\mathrm{ES}}\left(p_{L-1}\right)\right] \\
p_{\mathrm{T}} \leq p_{L}<p_{\mathrm{M}}: & \theta_{\mathrm{REF}}^{\mathrm{f}}\left(p_{\mathrm{L}}\right)=\theta_{\mathrm{ES}}\left(p_{\mathrm{L}}\right) \\
& -\frac{p_{\mathrm{L}}-p_{\mathrm{T}}}{p_{\mathrm{M}}-p_{\mathrm{T}}}\left\{\theta_{\mathrm{ES}}\left(p_{\mathrm{M}}\right)-\theta_{\mathrm{REF}}^{\mathrm{f}}\left(p_{\mathrm{M}}\right)\right\}
\end{array},\right.
$$

where $p_{\mathrm{M}}$ denotes the pressure at the freezing model level, $p_{\mathrm{L}}$ denotes the pressure at any model level in the cloudy air column (such that $L$ increases upwards from $p_{\mathrm{B}}$ to $p_{\mathrm{T}}$ ) and $p_{0}$ and $T_{0}$ the pressure and temperature at the level from which the air parcel is lifted. In the first equation the constant $\alpha$, according to Betts (1986), is equal to 0.85 but in the default WRF implementation it is set to 0.9 , corresponding to a steeper $d \theta_{\mathrm{REF}} / \mathrm{d} p$ or a statically more stable profile. This choice of 0.9 for $\alpha$ was made when the scheme was tuned to the model over the North American region (Z. Janjić, personal communication, 2013).

The corresponding first-guess reference temperature profile is

$T_{\mathrm{REF}}^{\mathrm{f}}\left(p_{\mathrm{L}}\right)=\theta_{\mathrm{REF}}^{\mathrm{f}}\left(p_{\mathrm{L}}\right) \Pi\left(p_{\mathrm{L}}\right)$,

with

$$
\Pi\left(p_{\mathrm{L}}\right)=\left(\frac{10^{5} \mathrm{~Pa}}{p_{\mathrm{L}}}\right)^{-R / c_{p}},
$$

where $\Pi\left(p_{\mathrm{L}}\right)$ is the Exner function (divided by $c_{P}$ ) for pressure $p_{\mathrm{L}}$ and $R$ is the specific gas constant for dry air.

At pressure $p_{\mathrm{L}}$ equal or lower than $200 \mathrm{hPa}$, the humidity field is not adjusted by the BMJ scheme. At pressure $p_{\mathrm{L}}$ larger than $200 \mathrm{hPa}$ in the convecting column, the first-guess reference specific humidity, $q_{\mathrm{REF}}^{\mathrm{f}}\left(p_{\mathrm{L}}\right)$, is prescribed by the lifting condensation level, $p_{\mathrm{L}}+\wp\left(p_{\mathrm{L}}\right)$, of an air parcel with $\theta_{\mathrm{REF}}\left(p_{\mathrm{L}}\right)$ and $q_{\mathrm{REF}}^{\mathrm{f}}\left(p_{\mathrm{L}}\right)$ at pressure $p_{\mathrm{L}}$,

$\left\{\begin{array}{lll}q_{\mathrm{REF}}\left(p_{\mathrm{L}}\right)=q\left(p_{\mathrm{L}}\right) & \text { if } & p_{\mathrm{L}} \leq p_{200} \\ q_{\mathrm{REF}}^{\mathrm{f}}\left(p_{\mathrm{L}}\right)=q^{*}\left(\theta_{\mathrm{REF}}^{\mathrm{f}}\left(p_{\mathrm{L}}\right), p_{\mathrm{L}}+\wp\left(p_{\mathrm{L}}\right)\right) & \text { if } & p_{\mathrm{L}}>p_{200}\end{array}\right.$,

where $p_{200}$ is the pressure of a model level just smaller or equal to $200 \mathrm{hPa}$. With the help of Tetens' formula (Tetens, 1930 ), the saturated specific humidity $q^{*}$ is given by

$$
\begin{aligned}
& q^{*}\left(\theta_{\mathrm{REF}}^{\mathrm{f}}\left(p_{\mathrm{L}}\right), p_{\mathrm{L}}+\wp\left(p_{\mathrm{L}}\right)\right)=\left(\frac{379.90516 \mathrm{~Pa}}{p_{\mathrm{L}}+\wp\left(p_{\mathrm{L}}\right)}\right) \\
& \operatorname{EXP}\left\{17.2693882\left(\frac{\theta_{\mathrm{REF}}^{\mathrm{f}}\left(p_{\mathrm{L}}\right)-\frac{273.16 \mathrm{~K}}{\Pi\left(p_{\mathrm{L}}+\wp\left(p_{\mathrm{L}}\right)\right)}}{\theta_{\mathrm{REF}}^{\mathrm{f}}\left(p_{\mathrm{L}}\right)-\frac{35.86 \mathrm{~K}}{\Pi\left(p_{\mathrm{L}}+\wp\left(p_{\mathrm{L}}\right)\right)}}\right)\right\} .
\end{aligned}
$$

The more negative $\wp\left(p_{\mathrm{L}}\right)$ is, the drier the reference profile is at pressure level $p_{\mathrm{L}} \cdot \wp\left(p_{\mathrm{L}}\right)$ is piecewise linearly interpolated between the values at the cloud bottom $\left(\wp_{\mathrm{B}}\right)$, freezing level 


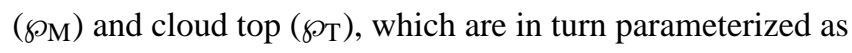
linear functions of cloud efficiency $E$ as follows:

$$
\begin{gathered}
\wp_{\mathrm{M}}=(-5875 \mathrm{~Pa})\left[F_{\mathrm{S}}+\left(F_{\mathrm{R}}-F_{\mathrm{S}}\right)\left(\frac{E^{\prime}-E_{1}}{E_{2}-E_{1}}\right)\right], \\
\wp_{\mathrm{B}}=(-3875 \mathrm{~Pa})\left[F_{\mathrm{S}}+\left(F_{\mathrm{R}}-F_{\mathrm{S}}\right)\left(\frac{E^{\prime}-E_{1}}{E_{2}-E_{1}}\right)\right], \\
\wp_{\mathrm{T}}=(-1875 \mathrm{~Pa})\left[F_{\mathrm{S}}+\left(F_{\mathrm{R}}-F_{\mathrm{S}}\right)\left(\frac{E^{\prime}-E_{1}}{E_{2}-E_{1}}\right)\right] .
\end{gathered}
$$

The constants in Pascals above were determined by Janjić (1994) and are not varied in this work. In the WRF version 3.3.1 implementation, the parameter $F_{\mathrm{R}}$ is set to 1 while $F_{\mathrm{S}}$ is set to 0.85 , an empirically determined value over the continental USA (Z. Janjić, personal communication, 2013), while in the Janjić (1994) $F_{\mathrm{S}}=0.6$. Evidently, with a higher value of $F_{\mathrm{S}}$, the formulation yields more negative $\wp\left(p_{\mathrm{L}}\right)$ and a drier reference humidity profile for each cloud efficiency, $E<E_{2}$. 
Acknowledgements. We are thankful to Bob Dattore (UCAR) for his help in downloading CFSR data through the CISL RDA website. This work comprises Earth Observatory of Singapore contribution no. 85. It is supported by the National Research Foundation Singapore and the Singapore Ministry of Education under the Research Centres of Excellence initiative. Special thanks are owed to Chee Kiat Teo, Yudha Djamil, Shunya Koseki, Jagabandhu Panda, Fang Wan, Ken Tay and Xianxiang Li, who generously made many constructive suggestions.

Edited by: K. Gierens

\section{References}

Arakawa, A. and Schubert, W. H.: Interaction of a cumulus cloud ensemble with the large-scale environment, Part I, J. Atmos. Sci., 31, 674-701, 1974.

Betts, A. K.: A new convective adjustment scheme. Part I: Observational and theoretical basis. Non-precipitating cumulus convection and its parameterization, Q. J. Roy. Meteorol. Soc., 112, 677-691, 1986

Betts, A. K. and Miller, M. J.: A new convective adjustment scheme. Part II: Single column tests using GATE wave, BOMEX, ATEX and arctic air-mass data sets, Q. J. Roy. Meteorol. Soc., 112, 693709, 1986.

Bowden, J. H., Otte, T. L., Nolte, C. G., and Otte, M. J.: Examining Interior Analysis nudging Techniques Using Two-Way Nesting in the WRF Model for Regional Climate Modeling, J. Climate, 25, 2805-2823, 2012.

Bowden, J. H., Nolte, C. G., and Otte, T. L.: Simulating the impact of the large-scale circulation on the 2-m temperature and precipitation climatology, Clim. Dynam. 40, 1903-1920, 2013.

Chen, F. and Dudhia, J.: Coupling an advanced land surfacehydrology model with the Penn State-NCAR MM5 modeling system. Part I: Model implementation and sensitivity, Mon. Weather Rev., 129, 569-585, 2001.

Chotamonsak, C., Salathe, E. P., Kreasuwan, K., Chantara, S., and Siriwitayakorn, K.: Projected climate change over Southeast Asia using a WRF regional climate model, Atmos. Sci. Lett., 12, 213-219, 2011

Chotamonsak, C., Salathe E. P., Kreasuwan, K., and Chantara, S.: Evaluation of Precipitation Simulations over Thailand using a WRF Regional Climate Model, Chiang Mai J. Sci., 39, 623-638, 2012

Davis, C., Wang, W., Chen, S. S., Chen, Y., Corbosiero, K., DeMaria, M., Dudhia, J., Holland, G., Klemp, J., Michalakes, J., Reeves, H., Rotunno, R., Snyder, C., and Xiao, Q.: Prediction of Landfalling Hurricanes with the Advanced Hurricane WRF Model, Mon. Weather Rev., 136, 1990-2005, 2008.

Done, J., Davis, C. A., and Weisman, M.: The next generation of NWP: explicit forecasts of convection using the weather research and forecasting (WRF) model, Atmos. Sci. Lett., 5, 100-117, 2004.

Emanuel, K. A.: A scheme for representing cumulus convection in large-scale models, J. Atmos. Sci., 48, 2313-2335, 2001.

Grell, G. A. and Dévényi, D.: A generalized approach to parameterizing convection combining ensemble and data assimilation techniques, Geophys. Res. Lett., 29, 14, doi:10.1209/2002GL015311, 2002.

Hong, S.-Y., Noh, Y., and Dudhia, J.: A New Vertical Diffusion Package with an Explicit Treatment of Entrainment Processes, Mon. Weather Rev., 134, 2318-2341, 2006.

Hoskins, B. J., Fonseca, R. M., Blackburn, M., and Jung, T.: Relaxing the Tropics to an 'observed' state: analysis using a simple baroclinic model, Q. J. Roy. Meteorol. Soc., 138, 1618-1626, 2012.

Huffman, G. J., Alder, R. F., Bolvin, D. T., Gu, G., Nelkin, E. J., Bowman, K. P., Hong, Y., Stocker, E. F., and Wolff, D. B.: The TRMM multisatellite image precipitation analysis (TMPA). Quasi-global, multi-year, combined-sensor precipitation estimates at fine scales, J. Hydrometeor., 8, 38-55, 2007.

Iacono, M. J., Delamere, J. S., Mlawer, E. J., Shephard, M. W., Clough, S. A., and Collins, W. D.: Radiative forcing by long-lived greenhouse gases: Calculations with the AER radiative transfer models, J. Geophys. Res., 113, D13103, doi:10.1029/2008JD009944, 2008.

Janjić, Z. I.: The step-mountain eta coordinate model: further developments of the convection, viscous sublayer and turbulence closure schemes, Mon. Weather Rev., 122, 927-945, 1994.

Kain, J. S.: The Kain-Fritsch convection parameterization: an update, J. Appl. Meteorol., 43, 170-181, 2004.

Kain, J. S. and Fritsch, J. M.: A one-dimensional entraining/detraining plume model and its application in convective parameterization, J. Atmos. Sci., 47, 2784-2802, 1990.

Kain, J. S. and Fritsch, J. M.: Convective parameterization for mesoscale models: the Kain-Fritsch scheme. The Representation of Cumulus Convection in Numerical Models, Meteorol. Monogr., 24, 165-170, Amer. Meteor. Soc., 1993.

Koh, T.-Y., Wang, S., and Bhatt, B. C.: A diagnostic suite to assess NWP performance, J. Geophys. Res., 117, D13109, doi:10.1029/2011JD017103, 2012.

Lim, K. and Hong, S.: Development of an effective double-moment cloud microphysics scheme with prognostic cloud condensation nuclei $(\mathrm{CCN})$ for weather and climate models, Mon. Weather Rev., 138, 1587-1612, 2010.

Miguez-Macho, G., Stenchikov, G. L., and Robock, A.: Regional climate simulations over North-America: interaction of local processes with improved large-scale flow, J. Climate, 18, 12271246, 2005.

Monin, A. S. and Obukhov, A. M.: Basic laws of turbulent mixing in the ground layer of the atmosphere, Trans. Geophys. Inst. Akad. Nauk USSR, 151, 163-187, 1954.

Ramage, C. S.: The role of a tropical "maritime continent" in the atmospheric circulation, Mon. Weather Rev., 96, 365-370, 1968.

Saha, S., Moorthi, S., Pan, H.-L., Wu, X., Wang, J., Nadiga, S., Tripp, P., Kistler, R., Woollen, J., Behringer, D., Liu, H., Stokes, D., Grumbine, R., Gayno, G., Wang, J., Hou, Y.-T., Chuang, H.Y., Juang, H.-M. H., Sela, J., Iredell, M., Treadon, R., Kleist, D., Delst, P. V., Keyser, D., Derber, J., Ek, M., Meng, J., Wei, H., Yang, R., Lord, S., Dool, H., Kumar, A., Wang, W., Long, C., Chelliah, M., Xue, Y., Huang, B., Schemm, J.-K., Ebisuzaki, W., Lin, R., Xie, P., Chen, M., Zhou, S., Huggins, W., Zou, C.-Z., Liu, Q., Chen, Y., Han, Y., Cucurull, L., Reynolds, R. W., Rutledge, G., and Goldberg, M.: The NCEP Climate Forecast System Reanalysis, B. Am. Meteorol. Soc., 91, 1015-1057, 2010. 
Samala, B. K., Nagaraju, C., Banerjee, S., Kaginalkar, S. A., and Dalvi, M.: Study of the Indian summer monsoon using WRFROMS regional coupled model simulations, Atmos. Sci. Lett., 14, 20-27, doi:10.1002/as12.409, 2013.

Skamarock, W. C., Klemp, J. B., Dudhia, J., Gill, D. O., Barker, D. M., Duda, M. G., Huang, X.-Y., Wang, W., and Powers, J. G.: A description of the Advanced Research WRF version 3, NCAR tech. Note TN-4175_STR, 113 p., 2008.

Stauffer, D. R. and Seaman, N. L.: Use of four-dimensional data assimilation in a limited area mesoscale model. Part I: experiments with synoptic-scale data, Mon. Weather Rev., 118, 1250-1277, 1990.

Stauffer, D. R., Seaman, N. L., and Binkowski, F. S.: Use of fourdimensional data assimilation in a limited-area mesoscale model. Part II: effects of data assimilation within the planetary boundary layer, Mon. Weather Rev., 119, 734-754, 1991.

Steele, C. J., Dorling, S. R., von Glasow, R., and Bacon, J.: Idealized WRF model sensitivity simulations of sea breeze types and their effects on offshore windfields, Atmos. Chem. Phys., 13, 443461, doi:10.5194/acp-13-443-2013, 2013.
Teo, C.-K., Koh, T.-Y., Lo, J. C.-F., and Bhatt, B. C.: Principal Component Analysis of observed and modelled diurnal rainfall in the Maritime Continent, J. Climate, 24, 4662-4675, 2011.

Tetens, V. O.: Über einige meteorologische Begriffe, Zeitschrift für Geophysik, 6, 297-309, 1930.

Ummenhofer, C. C., England, M. H., McIntosh, P. C., Meyers, G. A., Pook, M. J., Risbey, J. S., Gupta, A. S., and Taschetto, A. S.: What causes Southeast Australia's worst droughts?, Geophys. Res. Lett., 36, L04706, doi:10.1029/2008GL036801, 2009.

von Storch, H., Langenberg, H., and Feser, F.: A spectral nudging technique for dynamical downscaling purposes, Mon. Weather Rev., 128, 3664-3673, 2000.

Waldron, K. M., Peagle, J., and Horel, J. D.: Sensitivity of a spectrally filtered and nudged limited area model to outer model options, Mon. Weather Rev., 124, 529-547, 1996.

Zeng, X. and Beljaars, A.: A prognostic scheme of sea surface skin temperature for modeling and data assimilation, Geophys. Res. Lett., 32, L14605, doi:10.1029/2005GL023030, 2005. 